\title{
openheart Interaction between access choice and pharmacotherapy for coronary intervention: the results of a UK survey
}

\author{
Tim D Kinnaird, Nicholas Ossei-Gerning, Rito Mitra, Richard A Anderson
}

To cite: Kinnaird TD, OsseiGerning N, Mitra R, et al. Interaction between access choice and pharmacotherapy for coronary intervention: the results of a UK survey. Open Heart 2014;1:e000094. doi:10.1136/openhrt-2014000094

\section{- Additional material is available. To view please visit the journal online (http://dx. doi.org/10.1136/openhrt- 2014-000094).}

Received 26 February 2014 Revised 7 May 2014 Accepted 28 May 2014

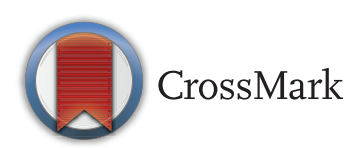

Department of Cardiology, University Hospital of Wales, Cardiff, UK

Correspondence to Dr Tim D Kinnaird; Tim.Kinnaird2@wales.nhs.uk

\section{ABSTRACT}

Introduction: Percutaneous coronary intervention (PCI) has changed significantly over the past decade with the uptake of radial access and the development of newer and more potent antiplatelets and safer antithrombins. This survey examined the default access route and pharmacology choice and their interaction in UK interventional practice.

Methods: An email-based survey invited interventional cardiologists to answer questions regarding arterial access and pharmacology use during $\mathrm{PCl}$.

Respondents were categorised into femoral, radial and radial $^{+}$(if the other radial was used rather than femoral if the right radial attempt failed). Data were analysed using $\chi^{2}$ or the Student t test.

Results: $81 \%$ of the 204 respondents reported the radial artery as their default access site with a significant interaction between years since qualification and access choice (21.1 years for radial ${ }^{+}$vs 23 years for radial ( $p=0.027)$ vs 26.6 years for femoral $(p=0.013)$ vs radial $(p=0.0005)$ vs radial $\left.{ }^{+}\right)$. There were 19 different combinations of access and pharmacology reported. For non-ST elevation myocardial infarction $\mathrm{PCl}$, there was a significant trend for radial ${ }^{+}$and radial operators to favour ticagrelor or tailored therapy versus femoral operators $(54.8 \%$ vs $47.8 \%$ vs $35 \%$, respectively, $\mathrm{p}=0.018)$. For primary $\mathrm{PCI}(\mathrm{PPCl})$, radial ${ }^{+}$ and radial operators were much more likely to choose ticagrelor or prasugrel than femoral operators $(77.2 \%$ ( $p<0.001)$ vs $73.9 \%$ ( $p=0.023)$ vs $50 \%$, respectively $(p<0.0001)$ for trend). For PPCl, glycoprotein inhibitor use was similar between groups ( $26.1 \%$ vs $25 \%$, not significant); radial operators were much more likely to choose bivalirudin $(52.8 \%$ vs $10 \%, p<0.0001)$ and much less likely to use heparin only $(19.8 \%$ vs $65 \%$, $p<0.0001)$ than femoral operators.

Conclusions: There is a significant interaction between years since qualification and access choice. Although there is no established consensus on access site or drugs, default radial operators are significantly more likely to utilise new generation antiplatelets and bivalirudin than femoral operators.

\section{INTRODUCTION}

Emerging novel techniques and technologies have significantly changed the way in which percutaneous coronary intervention (PCI) is

\section{KEY MESSAGES}

- From our study age appears to be associated with the use of the radial artery for coronary intervention.

- Conversely use of the radial artery is associated with a greater likelihood of adopting newer drugs such as prasugrel or bivalirudin for percutaneous coronary intervention (PCI).

- These associations might affect patient outcomes after $\mathrm{PCl}$ and are worthy of future studies.

delivered over the past decade. The emergence of the radial artery as a default access route has been supported by trials such as the RIVAL study indicating a morbidity (and in certain subgroups a mortality) reduction with routine use of the radial artery compared to the femoral artery. Indeed, in the UK, the popularity of the radial artery has increased linearly since 2004 with the most recent British Cardiovascular Intervention Society (BCIS) Central Cardiac Audit Database (CCAD) reporting $65.3 \%$ of all procedures as being performed radially in 2012. ${ }^{1}$ However, the same CCAD data also show a huge variation in the use of the radial artery with operator and centre rates varying from $0 \%$ to $100 \%$.

The introduction of newer and more potent antiplatelet drugs as an alternative to clopidogrel backed by recent clinical trials has provided further opportunities to improve patient outcomes. In the TRITON study, prasugrel reduced the occurrence of the primary end-point (death, myocardial infarction and stroke) in patients undergoing PCI for an acute coronary syndrome (ACS) by $19 \%$ versus clopidogrel. ${ }^{2}$ Similarly, the same primary end-point was reduced by $16 \%$ with ticagrelor when compared with clopidogrel in the PLATO study. ${ }^{3}{ }^{4}$ Despite these significant end-point reductions, as with access choice, the most recent CCAD data 
demonstrate widespread variation in the uptake of these newer drugs. ${ }^{1}$ For example, ticagrelor use by UK centres varies between $0 \%$ and $60 \%$ for patients presenting with an ACS and undergoing PCI.

Finally, several alternatives to a heparin-only approach for periprocedural adjunctive drug treatment have gained increasing acceptance over the past few years. Again, these novel therapies provide potential opportunities to improve patient outcomes over standard therapy. For example, the introduction of low-molecular-weight heparin (LMWH) in elective and ACS PCI is now supported by good clinical trial data. ${ }^{5}$ Additionally, although glycoprotein inhibitors (GPIs) remain a mainstay of therapy, bivalirudin has become increasingly popular following the publication of large clinical trials such as ACUITY and HORIZONS. ${ }^{7} 8$ As with access choice and antiplatelet use, the CCAD data reveal a lack of consensus in the use of adjunctive pharmacotherapy during PCI, findings which are at odds with the most recent European Society of Cardiology (ESC) guidelines on the use of adjuvant pharmacotherapies during PCI for non-ST elevation myocardial infarction (NSTEMI)/ STEMI. ${ }^{1}$

Although national audit data provide an insight into a centre's access and pharmacological strategies, no data are available on each individual's default choices. Additionally, there are no data on the interaction between access choice and pharmacology. Therefore, the purpose of this survey was to study the uptake of these new developments on an individual operator basis and to examine the interaction between access site, antiplatelet choice and adjunctive pharmacology use among UK interventional cardiologists.

\section{METHODS}

An email-based survey coordinated by a commercial webbased survey site (http://www.surveymonkey.com) invited interventional cardiologists to answer questions regarding arterial access and pharmacology use during PCI. The email invitation was sent to the lead cardiologist at every UK PCI centre with a request to forward it on to all interventional cardiology colleagues at that centre. A total of 99 centres were contacted. Additionally, the link was included in an article in the May 2013 BCIS newsletter which is sent out to every BCIS member. Respondents were invited to answer 10 questions regarding their default access route, antiplatelet drugs and adjunctive pharmacology use during PCI. Respondents were first asked to state their default access site for elective PCI, NSTEMI PCI and primary PCI (PPCI). Radial responders were then asked what their default bailout route was if an initial radial artery attempt failed. Respondents were categorised into femoral (for a default femoral approach for each indication), radial (for a default radial approach for each indication) and radial $^{+}$(if the default access site was the other radial rather than femoral if the initial radial attempt failed). When classifying operators as radial versus femoral operators, we did not question whether operators first attempted left or right radial access; both would be considered as radial (or radial ${ }^{+}$) operators. Respondents were then asked to define their antiplatelet choice in elective PCI, NSTEMI PPCI and PPCI with a choice of clopidogrel, prasugrel, ticagrelor or tailored therapy offered. The definition of tailored therapy for the purposes of this survey was simply defined as individualised therapy. Whether this was driven by platelet function testing or by clinical judgement was not questioned. For adjunctive therapy in NSTEMI PCI and PPCI, respondents were asked to choose heparin-only, LMWH-only, routine GPI use, bailout GPI use, routine bivalirudin use or bailout bivalirudin use as their default strategy. Finally, responders were asked to state their year of qualification from medical school. See online supplementary appendix 1 lists for the questions and possible answers.

Data were downloaded in an Excel spreadsheet format from SurveyMonkey.com to allow analysis and analysed by an external professional statistician. Data were expressed as a mean for continuous variables and as frequencies and percentages for categorical data. Continuous variables were compared using the Student $\mathrm{t}$ test. Categorical data were compared using the $\chi^{2}$ statistical test. The null hypothesis was rejected at the level $\mathrm{p}<0.05$.

\section{RESULTS \\ Access site}

A total of 204 responses were received, and thus the survey represents the practice of about one-third of the total UK interventional cardiologists (estimated to be 612 from the 2012 CCAD audit). ${ }^{1}$ There were no significant differences in access choice by indication with $81 \%$ of responders reporting the radial artery as their default access site for all three clinical scenarios (elective, NSTEMI and PPCI). Although the majority of operators reported the same access site regardless of the

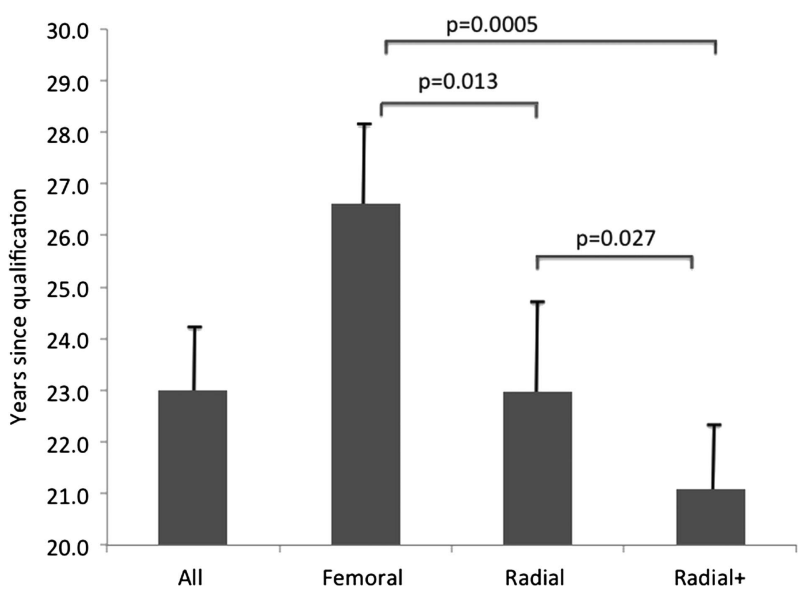

Figure 1 Interaction between years since qualification and access choice. 
presentation, three default femoral operators for elective and NSTEMI PCI reported the radial artery as their access choice for PPCI while four default radial operators for elective and NSTEMI routinely chose the femoral artery for PPCI access. The radial $^{+}$operators represented $29.9 \%$ of the responders.

There was a significant interaction between years since qualification and access choice (21.1 years for radial $^{+}$vs 23 years for radial $(p=0.027)$ vs 26.6 years for femoral $(p=0.013)$ vs radial $(p=0.0005)$ vs radial ${ }^{+}$; figure 1$)$.

\section{Antiplatelet choice}

In an elective PCI, there were no differences in antiplatelet choice between the femoral, radial and radial ${ }^{+}$ groups with clopidogrel dominating and minimal use of ticagrelor or prasugrel, in line with clinical evidence and guidelines. In NSTEMI PCI, for the whole study sample, clopidogrel was chosen by $52.4 \%$ of operators with ticagrelor $(27.8 \%)$ and tailored therapy $(16.5 \%)$ accounting for the majority of the remainder. However, when analysed by access route, radial $^{+}$and radial operators were more likely to favour ticagrelor or tailored therapy in comparison to femoral operators $(54.8 \%$ vs $47.8 \%$ vs $35 \%$, respectively, $\mathrm{p}<0.01$ for trend; table 1 ).

For PPCI, in the overall population, clopidogrel use was less prevalent $(28.3 \%)$ than prasugrel $(36.7 \%)$ or ticagrelor $(34.5 \%)$. In contrast to NSTEMI treatment, tailored therapy was rarely chosen as an option for PPCI $(<0.5 \%)$. As with NSTEMI treatment, there appeared to be an interaction between access choice and antiplatelet drug therapy. Radial operators were significantly more likely to choose ticagrelor than femoral operators $(35.7 \%$ vs $25 \%, \mathrm{p}=0.05)$, prasugrel than femoral operators $(38.2 \%$ vs $25 \%, \mathrm{p}<0.05)$ and ticagrelor or prasugrel than femoral operators $(73.9 \%$ vs $50 \%, \mathrm{p}=0.023$; table 2). Conversely, femoral operators much more frequently chose clopidogrel than radial operators for PPCI $(50 \%$ vs $25.5 \%, \mathrm{p}<0.001)$. The interaction between the access route and the antiplatelet choice was even more striking in the radial ${ }^{+}$group (ticagrelor use $45.2 \%$ vs $25 \%$ in the femoral group $(\mathrm{p}=0.018)$ and ticagrelor or prasugrel use $77.2 \%$ vs $50 \%$ in the femoral group ( $\mathrm{p}<0.001)$; table 2).

\begin{tabular}{|c|c|c|c|c|}
\hline & $\begin{array}{l}\text { All } \\
\text { (\%) }\end{array}$ & $\begin{array}{l}\text { Femoral } \\
(\%)\end{array}$ & $\begin{array}{l}\text { Radial } \\
(\%)\end{array}$ & $\begin{array}{l}\text { Radial }^{+} \\
(\%)\end{array}$ \\
\hline Clopidogrel & 52.4 & 60.0 & 50.3 & 50.2 \\
\hline Prasugrel & 1.9 & 5.0 & 1.3 & 0.0 \\
\hline Ticagrelor & 27.8 & 25.0 & 29.3 & 34 \\
\hline Tailored & 16.5 & 10.0 & 18.5 & 20.8 \\
\hline $\begin{array}{l}\text { Tailored or } \\
\text { ticagrelor }\end{array}$ & 45.3 & 35.0 & 47.8 & $54.8^{*}$ \\
\hline
\end{tabular}

${ }^{*} p<0.01$ for trend across groups.

NSTEMI, non-ST elevation myocardial infarction; PCI,

percutaneous coronary intervention.

\begin{tabular}{|c|c|c|c|c|}
\hline & $\begin{array}{l}\text { All } \\
(\%)\end{array}$ & $\begin{array}{l}\text { Femoral } \\
(\%)\end{array}$ & $\begin{array}{l}\text { Radial } \\
(\%(p \text { value }))^{*}\end{array}$ & $\begin{array}{l}\text { Radial+ } \\
(\%(p \text { value }))^{\star}\end{array}$ \\
\hline Clopidogrel & 28.3 & 50.0 & $25.5(<0.001)$ & $20.8(0.007) \dagger$ \\
\hline Prasugrel & 36.7 & 25.0 & $38.2(<0.05)$ & $32(0.06) \dagger$ \\
\hline Ticagrelor & 34.5 & 25.0 & $35.7(=0.05)$ & $45.2(0.018) \dagger$ \\
\hline $\begin{array}{l}\text { Prasugrel } \\
\text { or ticagrelor }\end{array}$ & 71.2 & 50.0 & $73.9(0.023)$ & $77.2(0.001) \dagger$ \\
\hline
\end{tabular}

\section{Adjunctive pharmacology during PCI}

During elective PCI, a heparin-only strategy was chosen by $95.4 \%$ of operators and LMWH-only by $4.6 \%$ of operators. There was no routine use of bivalirudin or GPIs. Although there was a trend for femoral operators to use more LMWH (15\% vs $3.8 \%$ for radial operators), there were no statistically significant interactions between access site and adjunctive drug choice during elective PCI. For NSTEMI PCI, a heparin-only strategy again dominated the responses $(77.4 \%)$ compared with LMWH-only $(7.3 \%)$, routine bivalirudin $(6.8 \%)$ and routine GPI (5.6\%). For bailout therapy, $60.1 \%$ of responders chose a GPI and $5.1 \%$ bivalirudin. All of the users of bailout bivalirudin were radial operators, but as with elective PCI, there were no statistically significant interactions between access site and adjunctive drug choice.

For PPCI, 23.7\% of operators chose a heparin-only strategy, $26.5 \%$ routine GPI use and $48.6 \%$ routine bivalirudin use. However, during PPCI, although GPI use was similar between groups ( $26.1 \%$ vs $25 \%$, p Value NS), radial operators were much more likely to choose bivalirudin $(52.8 \%$ vs $10 \%, \mathrm{p}<0.0001)$ and much less likely to use heparin-only $(19.8 \%$ vs $65 \%, \quad \mathrm{p}<0.0001)$ than femoral operators (table 3 and figure 2). Overall, radial operators were more than twice as likely to choose bivalirudin or a GPI than femoral operators $(78.9 \%$ vs $35 \%$, $\mathrm{p}<0.0001)$. Additionally, if a heparin-only strategy was not used, femoral operators were much more likely to choose a GPI than bivalirudin $(71.4 \%$ vs $33.2 \%$, $\mathrm{p}<0.001)$. A similar interaction was noted between access site and adjunctive pharmacology choice in the radial ${ }^{+}$ operator subgroup. For bailout, operators mostly chose a GPI $(40.7 \%)$ with a small amount of bivalirudin use $(1.7 \%)$. All of the bivalirudin bailout users were radial $^{+}$ access by default.

\section{Combinations of access site/antiplatelets/adjunctive pharmacology}

The survey results confirm the lack of consensus in access site, antiplatelet selection and adjunctive pharmacology use among UK interventional cardiologists. Although for elective PCI the combination of radial 
Table 3 Default adjunctive pharmacology choice for PPCI

\begin{tabular}{lllll}
\hline & All (\%) & Femoral (\%) & Radial (\% (p value)) $^{*}$ & Radial $^{+}\left(\%(\mathbf{p ~ v a l u e )})^{*}\right.$ \\
\hline Heparin only & 23.7 & 65.0 & $19.8(<0.0001)$ & $18.9(<0.0001)$ \\
Glycoprotein inhibitor & 26.5 & 25.0 & $26.1(\mathrm{NS})$ & $30.2(\mathrm{NS})$ \\
Bivalirudin & 48.6 & 10.0 & $52.8(<0.0001)$ & $47.1(<0.0001)$ \\
Glycoprotein inhibitor or bivalirudin & 75.1 & 35.0 & $78.9(<0.0001)$ & $77.3(0.0001)$ \\
\hline *Denotes p value when compared to femoral antiplatelet use. & &
\end{tabular}

access, clopidogrel and heparin dominated the majority of responses, in NSTEMI PCI there were 19 different combinations of access site/antiplatelets/adjunctive pharmacology reported and 17 different combinations reported for PPCI. Indeed, the variations would have been even more numerous had the responders been given the option to select exactly which GPI they favoured and the dose and route of administration. For NSTEMI PCI, the combination of radial access/clopidogrel/heparin-only was the most popular, accounting for $39.5 \%$ of responses, with the combination of radial access/ticagrelor/heparin-only in second place, accounting for $23.7 \%$ of responses. For PPCI, radial access/prasugrel/bivalirudin $(20.4 \%)$ and radial access/ticagrelor/ bivalirudin $(19.8 \%)$ were the most popular combinations.

\section{DISCUSSION}

The major findings of this study are: (1) there is a significant interaction between years since qualification for UK interventional cardiologists and the likelihood of routine radial artery use for PCI; (2) there is a significant interaction between access artery choice and antiplatelet selection for NSTEMI PCI and PPCI; (3) there is a significant interaction between access artery and periprocedural adjunctive pharmacology use for PPCI and (4) there is little consensus on which combination

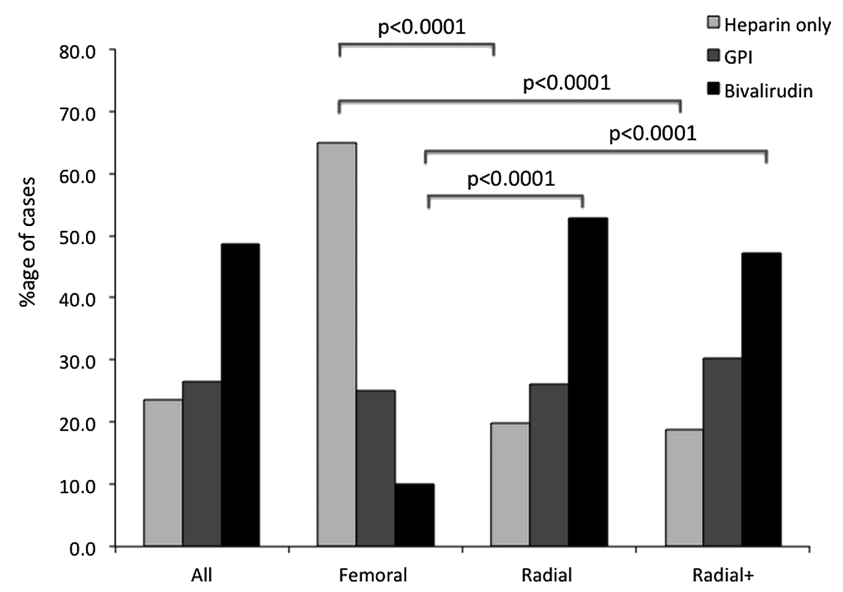

Figure 2 Choice of routine pharmacology for $\mathrm{PPCl}$ by default access route (GPI, glycoprotein inhibitor; PPCl, primary percutaneous coronary intervention). of arterial access and pharmacology is used. While variability in clinical practice is to be expected, the huge variation seen in this and other audits of UK interventional practice are surprising and run counter to current European guideline recommendations. ${ }^{9}$

In considering variations in default arterial access choice, these data, as well as CCAD audit data, record wide variations in the use of the radial artery with operator and centre rates varying from $0 \%$ to $100 \%$. In considering why changes in clinical practice lag behind new clinical evidence and guidance, although clinical trial data demonstrate a morbidity benefit (with significant reductions in vascular access site complications), evidence of a clear-cut mortality reduction is lacking. ${ }^{10-13}$ However, particular subgroups in these trials, such as high-volume centres/operators and PPCI, may have associated mortality improvements. ${ }^{9}$ As the result of a lack of a clear-cut mortality, signal radial artery access receives only modest support in clinical guidelines. For example, in the most recent NICE STEMI guidelines, interventional cardiologists are asked to "consider radial (in preference to femoral) arterial access for people undergoing coronary angiography (with follow-on primary PCI if indicated)." Additionally, the ESC STEMI guidelines state that if PPCI is to "be performed by an experienced radial operator, radial access should be preferred over femoral access (class of recommendation IIa, level of evidence B)." ${ }^{" 14}$ Other possible reasons for lack of uptake of the radial artery, apart from modest guideline support, include scepticism regarding the clinical trial data, inertia to change, perceived technical challenges in its performance, convictions regarding best practice and perhaps local internal audit data regarding procedural outcomes.

With respect to the lack of consensus in antiplatelet choice for PCI, the results of the two landmark trials of prasugrel and ticagrelor are broadly similar. $^{2-4}$ This factor, combined with the lack of a head-to-head trial of the two drugs, is the likely explanation for the lack of consensus among UK interventional cardiologists. Additionally, the ESC and American Heart Association (AHA) guidelines give a similar weight of recommendation for both drugs. ${ }^{15-17}$ For example, the ESC guidance awards IB to ticagrelor and prasugrel in NSTEMI management while in STEMI a similar weighting is also given to both drugs. ${ }^{15}{ }^{16}$ Perhaps what is surprising, however, is the persistence in UK practice of clopidogrel 
for NSTEMI PCI and even more strikingly for PPCI. This is despite the fact that the ESC STEMI and NSTEMI guidelines consider prasugrel and ticagrelor superior to clopidogrel. ${ }^{15} 16$ Although scepticism regarding data and inertia to change may partly explain this, it is also likely that cost is a significant factor in antiplatelet choice. Indeed, in a preliminary survey, $60 \%$ of respondents indicated that cost was a significant factor in their pharmacology choice (unpublished data).

In considering periprocedural adjunctive pharmacology, the preponderance of a heparin-only strategy for elective PCI is perhaps to be expected, although the infrequent use of routine GPI use for NSTEMI might be considered more surprising. Despite the ESC and AHA guidelines recommending bivalirudin over unfractionated heparin and a GPI for PPCI, almost one-quarter of operators chose a heparin-only strategy for PPCI. ${ }^{15} 17$ In contemporary PPCI practice, this is an untested approach but the results of the HEAT-PPCI trial results next year will add important data in guiding a heparin-only strategy. ${ }^{18}$ As with antiplatelet choice, factors influencing adjunctive therapy choice are likely to include scepticism regarding the clinical trial data, equal guideline support, inertia to change and cost.

The interaction between access site and pharmacology choice is fascinating and has not been documented previously. The reasons for the significant interactions noted in our study are unclear, but one simple explanation may be that several major determinants of change-that is scepticism regarding data, inertia to change, perceived technical challenges and convictions regarding best practice-are similarly influencing a change in practice in access site choice and pharmacology choice. However, while we can only speculate on the explanation for the interaction between access site and antiplatelet choice, another factor that may account for the association may be the risk of bleeding from femoral access. There is a wealth of clinical data linking femoral artery puncture with major bleeding and also linking major bleeding with adverse outcomes. ${ }^{19-23}$ Additionally, randomised control trials of GPIs demonstrate a significant excess of femoral access site bleeds over placebo. ${ }^{2425}$ Therefore, femoral operators may be cognisant of the risk of major bleeding when using GPIs during PPCI, and thus this might explain the excess use of a heparin-only strategy by femoral operators in comparison to radial operators (65\% vs 19.8\%). However, against this as a likely explanation is that the survey data also show that femoral operators (despite the proven marked reduction in femoral vascular access complications with bivalirudin vs a GPI) ${ }^{7826}$ were much more likely to choose a GPI than bivalirudin $(71.4 \%$ vs $33.2 \%$, $\mathrm{p}<0.001$ ) if not using a heparin-only strategy.

Bivalirudin use in the UK is restricted mainly to PPCI (17.5\% of cases in 2012 compared with $2 \%$ of NSTEMI PCI and $0.5 \%$ of stable angina PCI). ${ }^{1}$ However, in the current study, use of bivalirudin was seen in $48 \%$ of PPCI cases and this high rate in comparison to UK-wide figures is driven by very high bivalirudin use in the radial subgroup and the apparent willingness of radial operators to respond to a survey invitation when compared with femoral operators.

The relationship between use of the radial artery and the likelihood of adoption of newer technologies provides an interesting insight into mechanisms behind recent observations in access studies. For example, in the STEMI cohort of the RIVAL trial, although mortality was reduced in the radial subgroup, major bleeding (by trial definition) was not actually different between the radial and femoral access groups. Similarly, a recent meta-analysis of the trials comparing femoral and radial access for PPCI failed to find a statistically significant reduction in major bleeding despite a $47 \%$ reduction in mortality. ${ }^{27}$ Although there are several likely explanations for these observations (including trial underpowering and variable/overstringent definitions of major bleeding), the increasing use of newer technologies by radial operators might also be a contributory factor to improved outcomes.

\section{LIMITATIONS}

One inherent limitation of a questionnaire-based study is the responder bias introduced by its voluntary nature. Indeed, the high rate of default radial access in respondents $(81 \%$ vs $65 \%$ in the most recent CCAD) appears to suggest that the default radial operators are more willing to respond to a survey than default femoral operators. However, it seems unlikely that this bias would significantly affect the findings of this study, and indeed it is plausible that this responder bias may actually underestimate the strength of the interaction between access choice and pharmacology.

Additionally, although this survey reveals the preferred choices of UK interventional cardiologists, it does not necessarily reflect real-life daily practice. However, many factors such as local protocols and fiscal constraints might affect what can be prescribed, but the purpose of the survey was to exclude these constraints and enquire as to what interventional cardiologists would use in an ideal world.

Finally, given the restriction on the number of questions posed, no data were captured on the outcomes or annual PCI volumes of the respondents.

\section{CONCLUSIONS}

This study reveals that there is no consensus among UK interventional cardiologists on the choice of access site, antiplatelet use or periprocedural adjunctive therapy choice. However, default radial operators are significantly more likely to utilise new generation antiplatelets and bivalirudin than femoral operators. There exists a significant interaction between years since qualification and access choice. 
Contributors TDK generated the idea, designed and sent out the survey, and participated in the data generation and analysis, manuscript preparation and review. NO-G and RM participated in the data analysis and manuscript review. RAA assisted with the design of the survey and participated in the data analysis, manuscript preparation and review.

Funding This research received no specific grant from any funding agency in the public, commercial or not-for-profit sectors.

Competing interests None.

Provenance and peer review Not commissioned; externally peer reviewed.

Data sharing statement No additional data are available.

Open Access This is an Open Access article distributed in accordance with the Creative Commons Attribution Non Commercial (CC BY-NC 3.0) license, which permits others to distribute, remix, adapt, build upon this work noncommercially, and license their derivative works on different terms, provided the original work is properly cited and the use is non-commercial. See: http:// creativecommons.org/licenses/by-nc/3.0/

\section{REFERENCES}

1. BCIS audit returns for adult interventional procedures Jan 2012Dec 2012. http://www.bcis.org.uk/resources/BCIS_Audit_2012_for_ web_V2_14-10-2013.pdf

2. Wiviott SD, Braunwald E, McCabe $\mathrm{CH}$, et al:; TRITON-TIMI 38 Investigators. Prasugrel versus clopidogrel in patients with acute coronary syndromes. N Engl J Med 2007;357:2001-15.

3. Wallentin L, Becker RC, Budaj A, et al.; PLATO Investigators. Ticagrelor versus clopidogrel in patients with acute coronary syndromes. N Engl J Med 2009;361:1045-57.

4. Cannon CP, Harrington RA, James S, et al. Comparison of ticagrelor with clopidogrel in patients with a planned invasive strategy for acute coronary syndromes (PLATO): a randomised double-blind study. Lancet 2010;375:283-93.

5. Collet JP, Huber K, Cohen M, et al. A direct comparison of intravenous enoxaparin with unfractionated heparin in primary percutaneous coronary intervention (from the ATOLL Trial). Am J Cardiol 2013;112:1367-72.

6. Montalescot G, White HD, Gallo R, et al. Enoxaparin versus unfractionated heparin in elective percutaneous coronary intervention. N Engl J Med 2006;355:1006-17.

7. Stone GW, White HD, Ohman EM, et al. Bivalirudin in patients with acute coronary syndromes undergoing percutaneous coronary intervention: a subgroup analysis from the Acute Catheterization and Urgent Intervention Triage strategy (ACUITY) trial. Lancet 2007;369:907-19

8. Stone GW, Witzenbichler B, Guagliumi G, et al. Bivalirudin during primary $\mathrm{PCl}$ in acute myocardial infarction. $N$ Engl $\mathrm{J}$ Med 2008;358:2218-30.

9. Mehta SR, Jolly SS, Cairns J, et al. Effects of radial versus femoral artery access in patients with acute coronary syndromes with or without ST-segment elevation. J Am Coll Cardiol 2012;60:2490-9.

10. Jolly SS, Yusuf S, Cairns J, et al. Radial versus femoral access for coronary angiography and intervention in patients with acute coronary syndromes (RIVAL): a randomised, parallel group, multicentre trial. RIVAL trial group. Lancet 2011;377:1409-20.

11. Agostoni P, Biondi-Zoccai GG, de Benedictis ML, et al. Radial versus femoral approach for percutaneous coronary diagnostic and interventional procedures; systematic overview and meta-analysis of randomized trials. J Am Coll Cardiol 2004;44:349-56.

12. Mamas MA, Ratib K, Routledge $\mathrm{H}$, et al. Influence of arterial access site selection on outcomes in primary percutaneous coronary intervention: are the results of randomized trials achievable in clinical practice? JACC Cardiovasc Interv 2013;6:698-706.

13. Romagnoli E, Biondi-Zoccai G, Sciahbasi A, et al. Radial versus femoral randomized investigation in ST-segment elevation acute coronary syndrome: the RIFLE-STEACS (Radial Versus Femoral Randomized Investigation in ST-Elevation Acute Coronary Syndrome) study. J Am Coll Cardiol 2012;60:2481-9.

14. National Institute of Clinical Excellence Guidelines on the acute management of myocardial infarction with ST elevation 2013 Clinical Guideline. http://www.nice.org.uk/nicemedia/live/13300/62703/ 62703.pdf

15. Steg PG, James SK, Atar D, et al. ESC guidelines for the management of acute myocardial infarction in patients presenting with ST-segment elevation. Eur Heart J 2012;33:2569-619.

16. Hamm CW, Bassand JP, Agewall S, et al. ESC Committee for Practice Guidelines. ESC guidelines for the management of acute coronary syndromes in patients presenting without persistent ST-segment elevation: The Task Force for the management of acute coronary syndromes (ACS) in patients presenting without persistent ST-segment elevation of the European Society of Cardiology (ESC) Eur Heart J 2011;32:2999-3054.

17. O'Gara PT, Kushner F, Ascheim D, et al. 2013 ACCF/AHA guideline for the management of ST-elevation myocardial infarction: executive summary: a report of the American College of Cardiology Foundation/American Heart Association Task Force on Practice Guidelines. Circulation 2013;127:529-55.

18. How Effective Are Antithrombotic Therapies in Primary Percutaneous Coronary Intervention (HEAT-PPCI). http:// clinicaltrials.gov/ct2/show/NCT01519518?term=heat+ppci\&rank=1

19. Manoukian SV, Feit F, Mehran R, et al. Impact of major bleeding on 30-day mortality and clinical outcomes in patients with acute coronary syndromes: an analysis from the ACUITY Trial. J Am Coll Cardiol 2007;49:1362-8.

20. Rao SV, O'Grady K, Pieper KS, et al. A comparison of the clinical impact of bleeding measured by two different classifications among patients with acute coronary syndromes. J Am Coll Cardiol 2006;47:809-16.

21. Kinnaird TD, Stabile E, Mintz GS, et al. Incidence, predictors, and prognostic implications of bleeding and blood transfusion following percutaneous coronary interventions. Am J Cardiol 2003;92: 930-5.

22. Eikelboom JW, Mehta SR, Anand SS, et al. Adverse impact of bleeding on prognosis in patients with acute coronary syndromes. Circulation 2006;114:774-82.

23. Kinnaird TD, Anderson RA, Hill JM, et al. Bleeding during percutaneous intervention: tailoring the approach to minimise risk. Heart 2009:95:15-19.

24. Kirtane AJ, Piazza G, Murphy SA, et al. Correlates of bleeding events among moderate- to high-risk patients undergoing percutaneous coronary intervention and treated with eptifibatide: observations from the PROTECT-TIMI-30 trial. J Am Coll Cardiol 2006:47:2374-9.

25. ESPRIT Investigators. Enhanced Suppression of the Platelet Ilb/IIla Receptor with Integrilin Therapy. Novel dosing regimen of eptifibatide in planned coronary stent implantation (ESPRIT): a randomised, placebo-controlled trial. Lancet 2000;356: 2037-44.

26. Lincoff AM, Kleiman NS, Kereiakes DJ, et al. Long-term efficacy of bivalirudin and provisional glycoprotein Ilb/IIla blockade vs heparin and planned glycoprotein Ilb/llla blockade during percutaneous coronary revascularization: REPLACE-2 randomized trial. JAMA 2004;292:696-703.

27. Mamas M, Ratib K, Routledge $\mathrm{H}$, et al. Influence of access site selection on PCl-related adverse events in patients with STEMI: meta-analysis of randomised controlled trials. Heart 2012;98:303-11. 